\title{
The Economics of Marriage in China: How hukou and migration systems leave rural China men single
}

\author{
Yunxiu Kang, Mazni Hanis Mahfuz and Liangzhuo Yuan
}

\begin{abstract}
Contrary to a view that the number of unmarried women in the world is increasing due to the extinction of 'good' men, China today faces the converse:

More than 24 million Chinese men of marrying age could find themselves without spouses in 2020... Another researcher quoted by the newspaper, Wang Yuesheng, said men in poorer parts of China would be forced to accept marriages late in life or remain single for life... $\sim$ Discovery News (2010)

This paper focuses on the economic analysis of the impact of migration and the hukou system on the increased number of unmarried men in rural areas. We find that due to cultural issues as well as comparative advantage in home production versus income earning, women are more likely to leave rural areas of China.
\end{abstract}




\section{INTRODUCTION}

Statistics from the US Central Intelligence Agency show that in China, there are 106 men for every 100 women. In some rural areas of China the male-female ratio is as high as 130 men for every 100 women (Discovery News, 2010).

The mean age of marriage in China is increasing from 22.4 in 1982 to 23.3 in 2000 for women and 24.9 in 1982 to 25.1 in 2000 for men (United Nations Population Division, 2009). On the other hand, the portion of married men is lower compared to women with $91.3 \%$ of women in the age of 25-29 married compared to only $75.3 \%$ of men in the same range of age (United Nations Population Division, 2009).

Mc Kinsey \& Co. in their report entitled "Preparing for China's Urban Billion" indicated that approximately 103 million Chinese people migrated from rural to urban areas and estimated over 350 million people will add to the urban population by 2025 with internal migrants consisting of more than 240 million.

The hukou system is an essential household registration permit, like an internal passport. Each Chinese citizen is given a rural (agricultural) or urban (non-agricultural) hukou since 1950s. Only local hukou holders can receive local public services, such as social security, benefits and welfare that are all covered by local government budget, which means the difference of benefits can be significant across regions (Cheng 2010). A rural person who works in one city for his whole life may never be able to access city-level social benefits.

Hukous from different cities are valued differently. In Richburg's (2010) article, he states that the Beijing hukou is the most prized. An urban hukou means individuals can have better opportunities in choosing jobs and education as well as receiving social-welfare facilities. The social benefits related to the hukou depend on the state of the local economy. Since the reform and open policy from 1970s, the economic gap between cities (especially coastal cities) and the rural areas has grown wider. This means that a city hukou is more attractive to the rural person than before.

Since government subsidies are a scarce resource, it is quite difficult for a person to exchange a rural hukou for an urban one. One feasible way for most rural females is to marry individuals with city hukous. Inter-hukou marriage is becoming increasingly common. In 2005 , the probability that an urban boy marrying a rural girl increased by over 5\% after 1998 
(Nie and Xing, 2010). In the same time, the probability of a rural man marrying an urban woman hasn't changed by much. In addition to the preference for boys in China, the net 'export' of rural girls to the cities worsened the imbalance of the sex ratio in rural areas. However, according to traditional Chinese culture, boys must take care of their parents and receive the inheritance of land. Based on the law of China, only the rural hukou holders can own land. That's why rural males are not willing to give up their rural hukou rights.

\section{ECONOMIC ANALYSIS}

The marriage market is a highly competitive market and due to the gender gap, women hold the power to choose (China Economist, 2011). Assume the demand curve represents the price a rural man has to pay to get a wife and the supply curve represents the supply of single (and willing) women in rural areas.

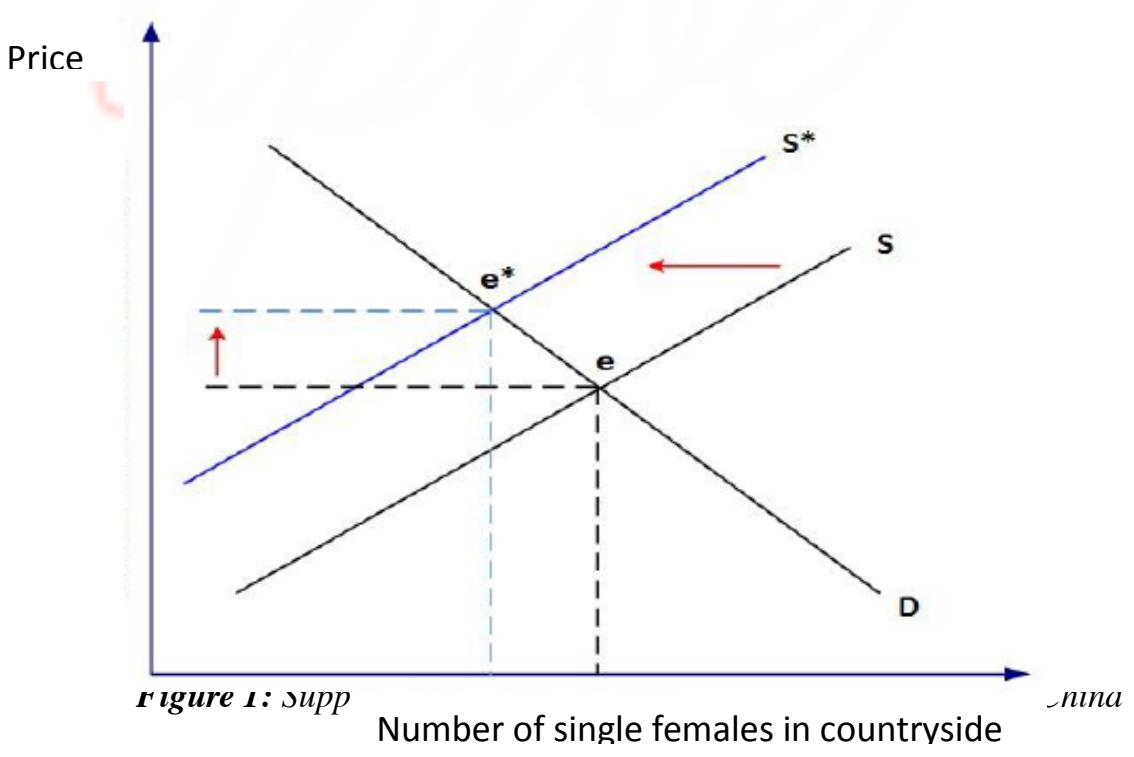


The migration of females from rural areas to the big cities has led the shift of supply curve to the left. This increases the equilibrium price from $e$ to $e^{*}$ which indicates a rise in the 'price' of females. Women in China are also becoming more highly-educated and financially independent. To adjust to this situation, men have to work harder, earn more money and increase their self-value to capture a woman's heart.

The opportunity cost if a woman chooses a city man over a rural man is giving up the previous social life as she has to adapt to the city's environment and lifestyle. Adapting to the city's hectic environment may be challenging and if she is not perpared mentally and psychologically, this may lead to stress. This can be represented with the production possibility frontier (PPF) below. We assume that in order for a woman to receive more money or social identity, she has to give up certain amount of 'love'. To earn more money, more time needs to be spent for work which means less time is spent together. 'Love' in this case refers to the time spent together between a married couple.

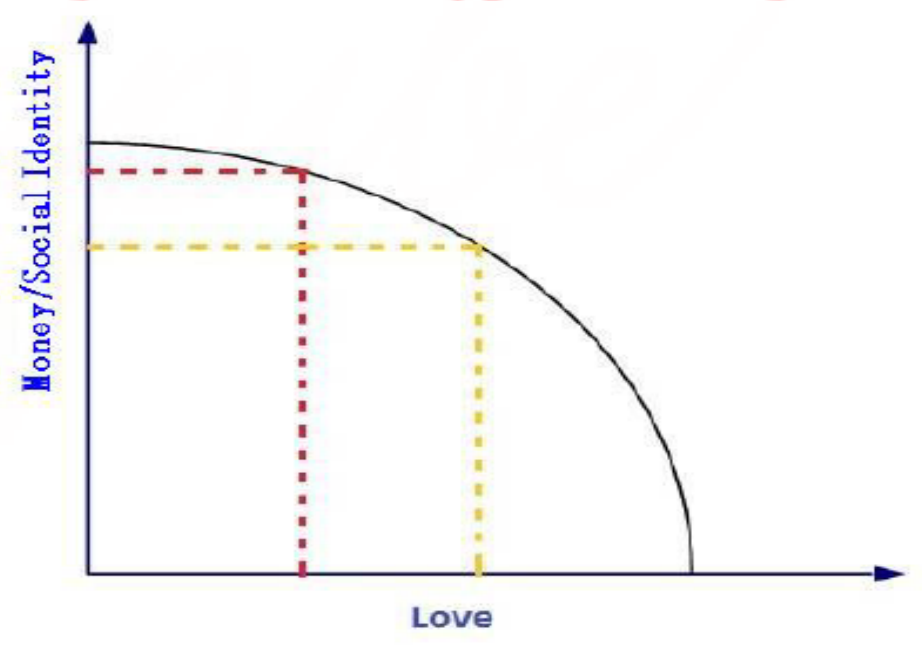

Figure 2: Production possibility frontier 
According to traditional Chinese values, the man is responsible for maintaining the whole family; meanwhile the woman is responsible for housework (Hays 2008). We restrict our focus on the material life of a family, which consists of family income and housework. Let us say, we divide the whole Chinese population into four groups, namely, 1) urban male, 2) urban female, 3) rural male and 4) rural female. From a purely income perspective, we can see the income gap from the table below:

Income gap decomposition

\begin{tabular}{|c|c|c|}
\hline & Males & Females \\
\hline \multicolumn{3}{|l|}{ Before correction for sample selection bias } \\
\hline Geometric mean of urban income, $\tilde{W}_{u}=e^{\hat{\lambda} \bar{X}_{2}+\hat{\gamma}_{2} \bar{\lambda}_{\mathrm{z}}}$ (yuan) & 207 & 154 \\
\hline Geometric mean of nural income, $\tilde{W}_{\mathrm{r}}=e^{3 \hat{P}_{\mathrm{t}}+\hat{\psi}_{\mathrm{r}} \bar{\lambda}_{\mathrm{t}}}$ (yulan) & 104 & 77 \\
\hline Relative income, $R=\tilde{W}_{\mathrm{u}} / \tilde{W}_{\mathrm{I}}$ & 1.99 & 2.00 \\
\hline
\end{tabular}

Source: http://www.cerium.ca/IMG/pdf/Zhu_The_Impacts_of_Income__China_economic.pdf

Economically speaking, the urban male group specialises in making money (207 Yuan per month) among the four groups. Meanwhile rural females who have less access to education have to stay at home and focus on housework. In contrast, urban females generally receive more education recourses and job opportunities than rural females; they therefore spend less time on housework. That is the reason why rural females specialise in housework. So that means when an urban male marries a rural female, the gains from the marriage will be relatively higher. The three graphs below show the gains from an inter-hukou marriage (urban male and rural female) are more than an intra-hukou marriage. 


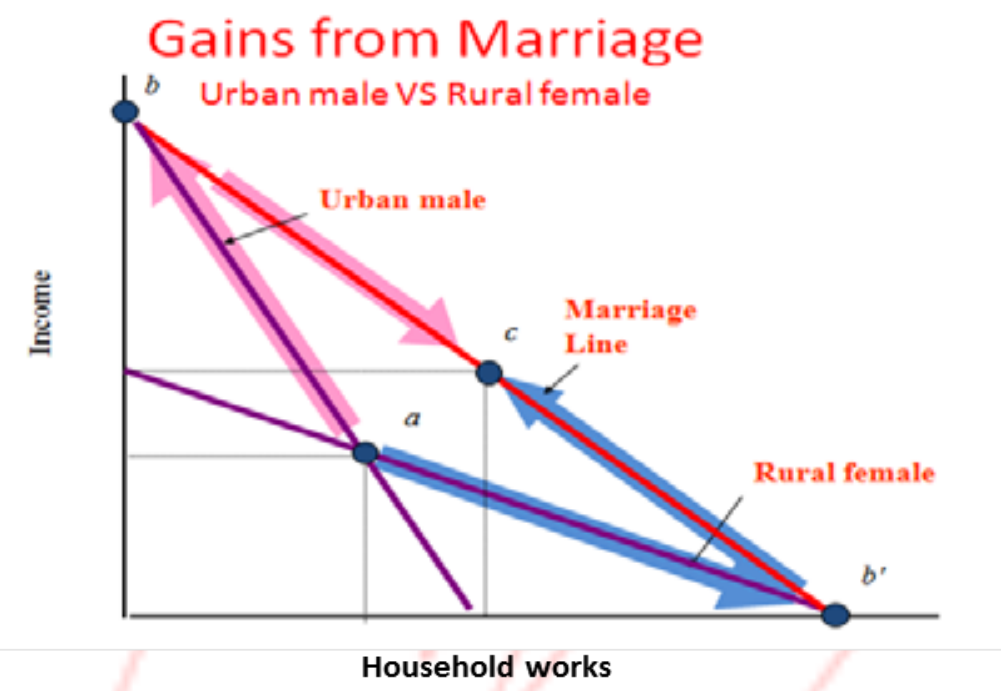

Figure 3: Gains from marriage (Urban male and Rural female)

\section{Gains from Marriage}

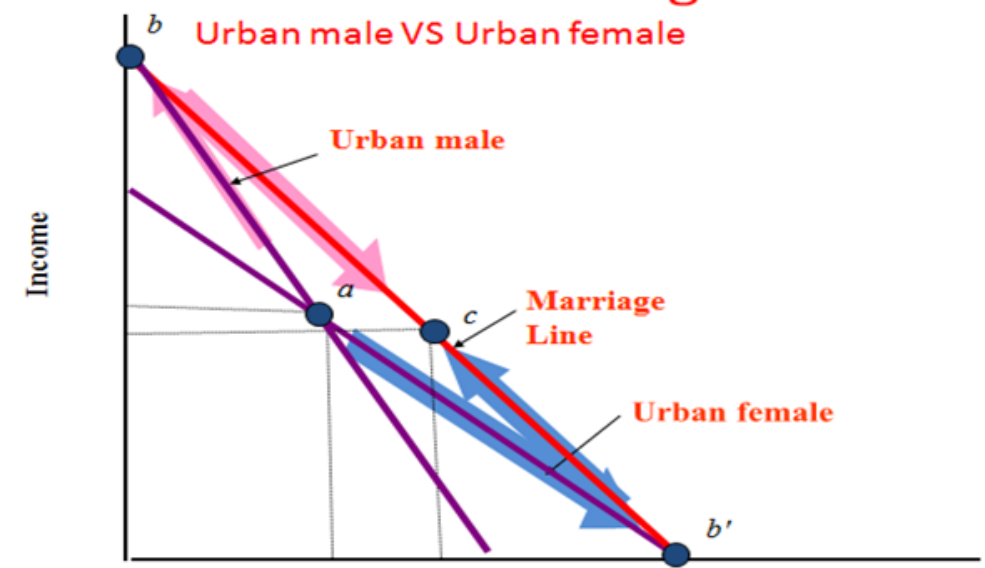

Household works

Figure 4: Gains from marriage (Urban male and Urban female) 
The last possibility is that an urban female marries a rural male. However this situation is least common because from a Chinese culture aspect, females always want to find a male with better social status and stronger financial background. Moreover, from economic aspect, the gains from specialisation in marriage will not be as large since rural males will still command decent economic opportunities.

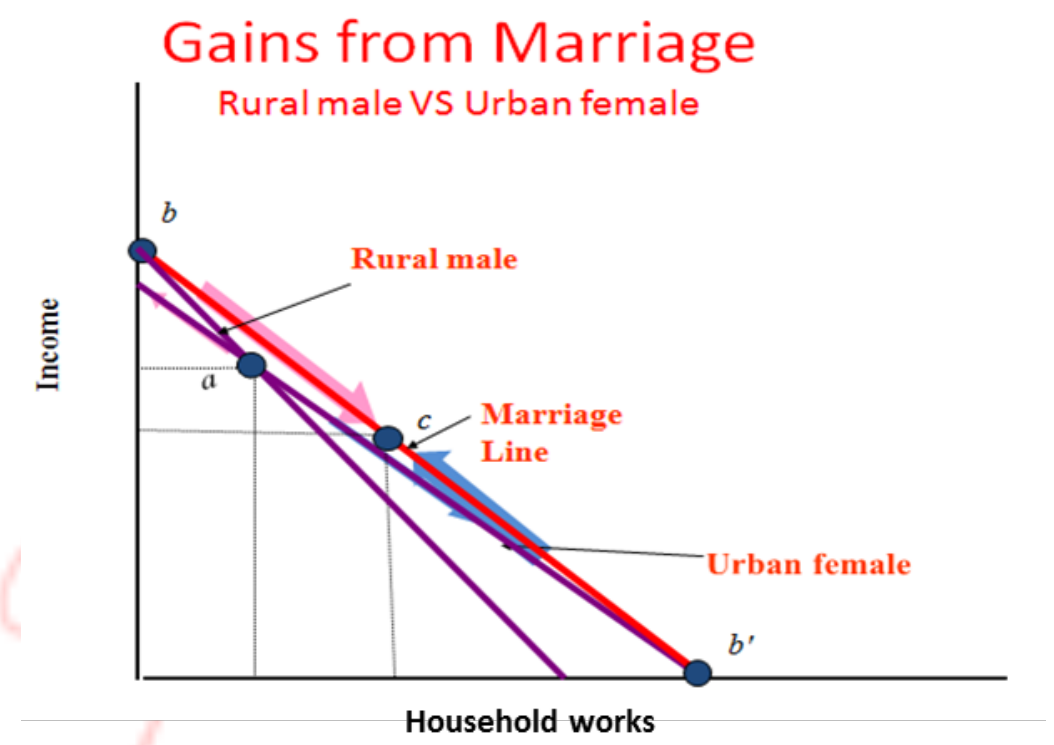

Figure 5: Gains from marriage (Rural male and Urban female)

\section{GOVERNMENT INTERVENTION}

To control the migration level and hukou system, the government of China has amended the policies. The hukou system has becoming more difficult to get in some big city like Beijing, Shanghai etcetera, as recent reforms often contain high income and strict housing requirements (Congressional-Executive Commission on China 2005). This includes "to qualify, applicants must have held a temporary Shanghai residency certificate and have been in the city's social insurance program for at least seven years, must be taxpayers, have 
obtained vocational qualifications at intermediate to high levels, and worked in pertinent fields, must have clean credit and criminal records" (Cheng 2010).

Furthermore, the government of some of the biggest cities like Beijing and Shanghai restrict marriage migration. They impose a series of extremely high requirements for an urban male who wants to transfer his wife from an agriculture hukou to urban hukou. The urban male needs a master degree with three years working experience or has to be a technician in a high-tech company or has to have a bachelor degree with a major in IT, telecommunications or an intermediate professional title (Cao 2009).

In order to decrease the imbalance of the gender gap, some modern cities have been encouraging young people who only have one child in the family to have a second child. Shanghai is taking its first step to reverse the one-child policy (Elegant 2009). This process is to reduce the proportion of the aging people and improve workforce scarcity in the future (Elegant 2009). There would be more urban males and females, which also means there will be decreasing demand for 'importing' rural females, and hence a reduction in the gender gap in rural areas.

\section{CONCLUSION}

The city hukou offers better prospects for jobs, health, education and social-welfare facilities (as per Appendix A). Those who have them also enjoy more government subsidies and facilities than individuals with a rural hukou. It is quite difficult for a person to change from a rural hukou to an urban hukou. There are some requirements such as a high education background, important tax contributions to the city government, or a specialist in one's field. One of the most feasible ways is for a rural individual to migrate and marry a city individual. Because of culture and the economics of specialisation, the most likely scenario is where a rural woman migrates by marrying an urban man.

The Chinese government has revised the hukou and inter-hukou marriage policy in order to balance the gender gap. The government is also currently encouraging every family to have more than one child to improve the workforce scarcity and at the same time to close the gender gap in the future. With these government interventions, the number of unmarried rural males may decline to a more balanced level in the future. 


\section{References}

Cao L. (2009). Shanghai Details New Hukou Policy, China Daily, retrieved 6 Sep 2011, $<$ http://www.chinadaily.com.cn/china/2009-02/24/content_7507915.htm>.

Central Intelligence Agency. (2011). The World Factbook, retrieved 06 September 2011, $<$ https://www.cia.gov/library/publications/the-world-factbook/geos/ch.html\#People>.

Cheng X.B. (2010). 'Shanghai's Hukou System reform', China Today-Explaining China to the World, December, retrieved 29 August 2011, <http://www.chinatoday.com.cn/ctenglish/se/txt/200905/04/content 193781.htm>.

China Economist (2011). 'Economics of Marriage and Real Estate in China', China Economics Blog, 20 April, retrieved 06 September 2011, <http://china-economicsblog.blogspot.com/2011/04/economics-of-marriage-and-real-estate.html>.

Congressional-Executive Commission on China (2005). 'China's Household Registration (Hukou) System: Discrimination and Reform', retrieved 29 August 2011, $<$ http://www.cecc.gov/pages/roundtables/090205/index.php>.

Dasgupta M, Ebenstein A and Sharygin E.J. (2011). 'China's Bride Shortage and Upcoming Challenges for Elderly Men', retrieved 11 September 2011, $<$ http://pluto.huji.ac.il/ ebenstein/DasGupta_Ebenstein_Sharygin_Marriage_January_2011.pdf $>$.

Discovery News (2010). 'China’s Gender Gap Leaves Millions of Single Men’, retrieved 05 September 2011, <http://news.discovery.com/human/china-birth-rate-single-men.html>.

Elegant S. (2009). 'Is China's One-Child Policy Heading For A Revision?', TimeWorld, July 27, retrieved 11 September 2011, $<$ http://www.time.com/time/world/article/0,8599,1912936,00.html>.

Hays J. (2008). 'Women, their Status, Confucianism, Villages in China', retrieved 21 Nov 2011, http://factsanddetails.com/china.php?itemid=105 
Nie H and Xing C. (2011). When City Boy Falls in Love with Country Girl: Baby's Hukou, Hukou Reform, and Inter-Hukou Marriage, retrieved 29 August 2011, $<$ http://www.iza.org/conference_files/ReLabEco2010/xing_c5544.pdf>

Richburg K.B. (2010). 'China hukou system deemed outdated as way of controlling access to services', Shanghai Express, 15 August, retrieved 29 August 2011, <http://shangaiexpress.blogspot.com/2010/08/china-hukou-system.html>.

United Nations Population Division (2009). World Marriage Data 2008, retrieved 05 September 2011, <http://www.un.org/esa/population/publications/WMD2008/WP_WMD_2008/Data.html>.

Zhao X. (2010). 'Dating TV in China: Don't talk to me unless you're rich', China Buzz, retrieved 11 September $2011,<$ http://www.cnngo.com/shanghai/life/reality-tv-comes-china-dont-talk-meunless-youre-rich-656443>. 


\section{Appendix A}

Table A1: Net Female Migration by Province and Provincial Characteristics

\begin{tabular}{|c|c|c|c|c|c|c|c|}
\hline \multirow[b]{2}{*}{ Province } & \multirow{2}{*}{$\begin{array}{c}\text { Net Female } \\
\text { Marriage } \\
\text { Migrants } \\
\text { (1995-2000) }\end{array}$} & \multicolumn{2}{|c|}{$\begin{array}{l}\text { GDP Per Capita } \\
(2006)\end{array}$} & \multirow{2}{*}{$\begin{array}{c}\text { Dependency } \\
\text { Ratio } \\
(2006) \\
\end{array}$} & \multirow{2}{*}{$\begin{array}{l}\text { Percent } \\
\text { Rural } \\
(2006)\end{array}$} & \multirow{2}{*}{$\begin{array}{c}\text { Life } \\
\text { Expectancy } \\
\text { at Birth } \\
(2000) \\
\end{array}$} & \multirow{2}{*}{$\begin{array}{c}\text { Percent of } \\
\text { Males } 30+ \\
\text { Never } \\
\text { Married }{ }^{+} \\
(2030)\end{array}$} \\
\hline & & Nominal & Quintile & & & & \\
\hline Jiangsu & 176,000 & 33,928 & 1 & 12.4 & 48.1 & 73.9 & $6.14 \%$ \\
\hline Guangdong & 99,000 & 33,151 & 1 & 8.9 & 37.0 & 73.3 & $5.67 \%$ \\
\hline Zhejiang & 96,000 & 37,411 & 1 & 12.2 & 43.5 & 74.7 & $7.58 \%$ \\
\hline Shandong & 65,000 & 27,807 & 2 & 11.4 & 53.9 & 73.9 & $6.33 \%$ \\
\hline Beijing & 62,000 & 58,204 & 1 & 10.8 & 15.7 & 76.1 & $3.13 \%$ \\
\hline Liaoning & 43,000 & 25,729 & 2 & 10.6 & 41.0 & 73.3 & $5.92 \%$ \\
\hline Shanghai & 42,000 & 66,367 & 1 & 15.0 & 11.3 & 78.1 & $3.98 \%$ \\
\hline Tianjin & 30,000 & 46,122 & 1 & 11.2 & 24.3 & 74.9 & $4.60 \%$ \\
\hline Hebei & 29,000 & 19,877 & 2 & 10.0 & 61.6 & 72.5 & $6.73 \%$ \\
\hline Xinjiang & 26,000 & 16,999 & 3 & 6.9 & 62.1 & 67.4 & $8.44 \%$ \\
\hline Fujian & 22,000 & 25,908 & 2 & 9.5 & 52.0 & 72.6 & $8.09 \%$ \\
\hline Shanxi & 13,000 & 16,945 & 3 & 9.3 & 57.0 & 71.7 & $6.38 \%$ \\
\hline
\end{tabular}

Source: http://pluto.huji.ac.il/ ebenstein/DasGupta_Ebenstein_Sharygin_Marriage_January_2011.pdf

\begin{tabular}{ll}
\hline \multicolumn{2}{l}{ Table 4: Legal minimum wage by selected Chinese cities, as of August 20 } \\
& Wage (RMB/month) \\
Chengdu, Sichuan Province & 450 or 550 or 650 [location-specific] \\
Zhengzhou, Henan Province & 600 or 700 or 800 [location-specific] \\
Chongqing & 680 \\
Taiyuan, Shanxi Province & 850 \\
Beijing & 900 \\
Langfang, Hebei Province & 900 \\
Wuhan, Hubei Province & 900 \\
Tianjin & 920 \\
Yantai, Shandong Province & 920 \\
Kunshan, Jiangsu Province & 960 \\
Hangzhou, Zhejiang Province & 1,100 \\
Shenzhen & 1,100 \\
Shanghai & 1,120 \\
\hline Source: China's &
\end{tabular}

Source: China's Ministry of Human Resources and Social Security, 2010. 